\title{
Altmetrics as a research specialty (Dimensions, 2005-2018)
}

\author{
Carlos Olmeda-Gómez; Antonio Perianes-Rodríguez
}

Nota: Este artículo se puede leer en español en:

https://recyt.fecyt.es/index.php/EPI/article/view/71626

How to quote this article:

Olmeda-Gómez, Carlos; Perianes-Rodríguez, Antonio (2019). "Altmetrics as a research specialty (Dimensions, 2005-2018)". El profesional de la información, v. 28, n. 6, e280608.

https://doi.org/10.3145/epi.2019.nov.08

Manuscript received on $20^{\text {th }}$ March 2019 Accepted on $25^{\text {th }}$ October 2019

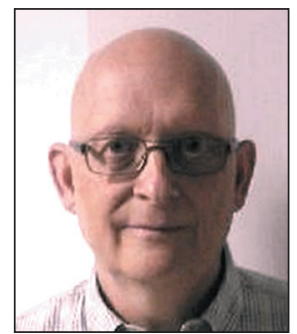

\author{
Carlos Olmeda-Gómez $\bowtie$ \\ https://orcid.org/0000-0001-5955-6423 \\ Universidad Carlos III de Madrid \\ Dpto. de Biblioteconomía y \\ Documentación. \\ Madrid, 128 \\ 28903 Getafe (Madrid), Spain \\ carlos.olmeda@uc3m.es
}

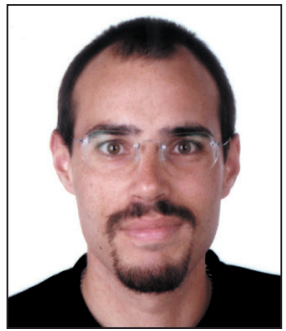

Antonio Perianes-Rodríguez https://orcid.org/0000-0002-1188-3481

Universidad Carlos III de Madrid

Dpto. de Biblioteconomía y

Documentación.

Madrid, 128

28903 Getafe (Madrid), Spain

antonio.perianes@uc3m.es

\begin{abstract}
The scientific literature on altmetrics published from 2005 to 2018 was analysed. The overall structure of the speciality's intellectual landscape is depicted through clusters of co-cited references, analysing journal and author co-citations. The 56,936 references cited in the 8,145 papers of all kinds retrieved from the Dimensions bibliographic database were included in the initial dataset used in the analysis. Pathfinder networks were generated with CiteSpace to determine the most prevalent journals and authors in the speciality. Conceptual structures were identified by co-citation clustering and latent semantic analysis. 'Open knowledge', 'altmetric collection', 'web indicator', 'assessing research', 'ResearchGate score', 'open data citation advantage', 'Google Scholar author citation', 'share data', 'academic tweet', 'Mendeley readership count' and 'social media metrics' were observed to be the lines of research presently favoured by specialists. Statistical indicators were calculated to determine the journals and contributors making the greatest impact.
\end{abstract}

\section{Keywords}

Altmetrics; Citation; Citation network analysis; Co-citation analysis; Visualization of citation networks; Scholarly social media; Indicators; Authors; Scientific journals; Scholarly communication; Science mapping; Dimensions; CiteSpace.

\section{Introduction}

The introduction of alternative metrics or 'altmetrics' in global scientific communication would not have been possible without the advent of new social network platforms around the time the internet bubble burst (1997-2000). In the runup to the $2001 \mathrm{crash}$ in the late nineteen nineties and subsequent Web 2.0 boom a strong economic environment driven by the ready availability of venture capital favoured the creation of social platforms such as Blogger (1999), Wikipedia (2001), Myspace (2003), Facebook (2004), Flickr (2004), YouTube (2005) and Twitter (2006) (0'Reilly, 2006). These platforms have been defined as

"a group of Internet-based applications that build on the ideological and technological foundations of Web 2.0, and that allow the creation and exchange of user generated content" (Kaplan; Haenlein, 2010).

\section{Acknowledgements}

The authors thank the anonymous reviewers whose comments have contributed to improving the article. The authors thank Margaret Clark, translator, for her linguistic support. 
In October 2010 Jason Priem, Dario Taborelli, Paul Groth and Cameron Neylon published the well known Altmetrics manifesto (Priem et al., 2010) contending that the impact of scientific activities has to be measured in the communication ecosystem comprising new types of services and modern online tools.

http://altmetrics.org/manifesto

According to those authors, the global impact of scientific activity and journal quality should be measured with parameters other than used in the past such as peer review, citation counts or the impact factor (IF), all created by the scientific community itself. The Manifesto's objections to peer review were that it

"is slow, encourages conventionality, and fails to hold reviewers accountable".

While admitting the utility of citation counting, the authors criticised the long timeframes involved, the neglect of impact outside the academic community, and the absence of information on the context or reasons for citations. The text identified as flaws in journals' IF that it is incorrectly used to assess individual scientific careers, its exact details remain a trade secret and it can be gamed fairly easy. These authors' initial aim was to find a way to replace traditional metrics based on citations in articles and scientific conference papers in assessment procedures.

Altmetrics is a term with many definitions. Thelwall noted that such metrics are

"derived from social websites, such as Twitter, that are free to join and open to the public (...) typically collected by a computer program through an applications programming interface" (Thelwall, 2017).

The conceit would encompass all the metrics that measure new ways of conducting, discussing or communicating science, particularly on user-generated content platforms. Such metrics would reinforce others previously in place and known generically as 'web indicators', associated with web-related quantitative studies (Thelwall; Vaughan; Björneborn, 2005; Mas-Bleda; Aguillo, 2015). A number of data sources are routinely used to obtain indicators (Weller, 2015). Generically and non-exhaustively, the user-generated content platforms cited here include those geared to social activity such as:

- Twitter and Facebook,

- academic activity loosely interpreted such as altmetric data aggregators (Altmetrics.com),

- reference managers (Mendeley),

- exchange libraries, and professional networks (Academia.edu; Faculty of 1000; ResearchGate) and,

- a variety of blog systems as well as those more scientifically oriented, with academic commentary and conversations.

Also considered are conventional and digital mass media targeting the public at large, including the press, audio-visual platforms such as YouTube and websites such as Wikipedia, where the citations received by an article or the number of times it is referenced can be counted (Priem, 2014).

Objections have been raised to the use of such new indicators

Voices have been raised, however, objecting to the use of such new indicators. Further to the arguments wielded they are inadequate:

- for constituting mere supplements to rather than replacements for citation-based indictor;

- for the ease with which they can be fraudulently gamed;

- for the absence of any correlation with bibliometric indicators;

- for the inclusion of social network data much less related to research results than to fads;

- for the lack of consensus on the meaning of what indicators measure;

- for the disparity of user motivations for mentioning a paper on social platforms;

- for the absence of a theoretical basis to interpret the indicators;

- and for the problems stemming from data quality and reproducibility, the non-inclusion of all digital media platforms and the language bias in the sources (Williams, 2017).

In recent years researchers engaging in the field have been particularly active, as attested to by the many sessions specifically addressing the subject in web congresses (2011-2014) and the hosts of dedicated altmetrics workshops held (2015-2018). In 2013 the U.S. National Information Standards Organization (NISO) received funding from the Alfred P. Sloan Foundation to implement a project defining standards and good practice, which were to be based on metrics in use and applicable to the area of research assessment. The organisation published its recommendations in 2016 (NISO, 2016).

The publication of a number of literature reviews (Thelwall; Kousha, 2015a; 2015b; Kousha; Thelwall, 2015; Erdt et al., 2016; Sugimoto et al., 2017) and the founding of a new open-access, peer-reviewed international journal in 2018, Journal of altmetrics, specifically focusing on alternative metrics, bear witness to the growth in research in and public visibility of the field over the last 10 years.

The bibliometric characterisation of altmetrics was explored by earlier authors who compiled data on output over time, identifying the most prominent authors, institutions or journals and estimating their impact. In 2014, for instance, a study of 70 records retrieved from Scopus between 2009 and 2014 listed output and impact based on Google Scholar data (Das; Mishra, 2014). In 2016, an analysis based on 253 Web of Science- and Scopus-listed papers published between 
2005 and 2015 identified the most prolific authors, institutions and journals, building co-authorship and keyword concurrence networks to describe subject focus (González-Valiente; Pacheco-Mendoza; Arencibia-Jorge, 2016). The editorial to the first issue of the Journal of altmetrics (Bar-Ilan, 2018) analysed altmetric indicators from Mendeley, Twitter, blogs and Wikipedia retrieved from the Altmetrics.com and PlumX platforms to obtain values for 693 papers indexed in Scopus and Web of Science.

The present paper presents new empirical data on inter-researcher intellectual relationships gleaned from citations networks established over more than a decade and identifiable through the papers listed in bibliographic databases.

\section{Objectives}

This study aimed primarily to determine the intellectual structure of alternative metrics (altmetrics) studies based on an analysis of bibliographic sources. The idea was to approximately describe the intellectual core of this research speciality. The approach consisted in a multi-level study with CiteSpace as a visualisation and citation network analytical tool. The secondary objectives pursued were to:

a) present data characterising the structure of altmetrics journals and publications;

b) identify the most influential authors and groups of authors working in the speciality;

c) obtain relational and citation indicators for individual authors and journals;

d) ascertain speciality-related conceits and terms; and

e) chart author- and journal-based co-citation maps.

\section{Materials and methods}

\subsection{Bibliographic records}

Bibliographic records were downloaded from the publications module in the open access version of Dimensions, the research data platform developed by Digital Science.

https://www.dimensions.ai

The platform also offers subscription access to modules on clinical tests, political reports, patents and subsidies (Orduña-Malea; Delgado-López-Cózar, 2018). When the data were downloaded, the headings in place in the Dimensions publication module were:

- articles (83 729633 )

- book chapters (8 729633 )

- conference papers (5 460221 )

- monographs (666 228)

- pre-prints (394 331)

- books (259 228).

In February 2019 the OA version of Dimensions was queried with the search statement altmetric OR altmetrics OR science 2.0 OR article level metrics OR social media metrics

This search statement is a modified version of one used in an earlier study (González-Valiente; Pacheco-Mendoza; Arencibia-Jorge, 2016). The sole additional syntagma in the argument, science 2.0, was included to capture a significant factor: how research is communicated and reaches a broader public through social media, grey sources or the web in general. The idea was to initially and intuitively include in the analysis the interactions among such audiences and a wide spectrum of new platforms and academic objects from which non-conventional research findings derive. Altmetrics was understood to be diverse and dynamic and, like other specialities, multi-faceted and multi-dimensional. As the authors engaging in this emerging speciality were deemed prone to relating their research to a very wide range of terms and periodicals, the statement used in the aforementioned study was enlarged. The option defined in the search interface was 'full data activated' and no date or other manner of filters, such as type of document, subject area or language, was established a priori.

The data were downloaded for the years 2005 to 2018. The records for 2019 (224) were deliberately excluded from the analysis, given that they were necessarily incomplete in February of that year. The year 2005 was defined as the first in the series because it was the first for which Dimensions returned 10 articles in response to the query. A manual inspection revealed that the references from earlier years were inappropriate. The records downloaded were subsequently analysed using the computational and statistical techniques embedded in CiteSpace V software (Chen, 2006).

\subsection{Methods}

A research speciality can be narrowly defined as

"the consensual structure of concepts in a field employed through its citation and co-citation network" (Morris; Van-der-Veer-Martens, 2008). 
Further to that definition, co-citation analysis was conducted of some of the entities identified in the bibliographic records. The co-citation perspective has been pivotal to bibliometric studies since the nineteen seventies for analysing specialities, schools or scientific fields. In other words, this conventional method was applied to analyse alternative metrics research.

The method chosen is generically known as author (White; Griffith, 1981) and journal (McCain, 1991) co-citation. Co-citation values reflect the number of times the names of two authors or two journals are jointly cited in later documents. The assumption is that the authors of the latter perceive the two objects to be related on the grounds of subject matter or methodology. When other authors in further papers cite the same objects in their lists of references, the content or methodologies of the objects cited are deduced to be even more closely shared. The stronger the co-citation bond between the two, the closer are the authors and journals comprising such relationships.

This study used graphic visualisation with the object nodes representing authors or journals and the connecting links or edges the strength of the bond or other attributes of the internodal relationship. Bibliometric maps were then charted from the graphs. Such scientograms depict the authors or journals pivotal or peripheral to the speciality, distinguishing the most from the least prominent. This study was not confined to merely building document co-citation clusters, however, but also and essentially consisted in analysing the composition of the clusters of citing documents, assigned or otherwise to co-citation clusters. The findings addressed both citing papers and the papers grouped in clusters of co-cited documents. The method chosen was consequently co-citation analysis (Boyack; Klavans, 2010).

\subsection{Procedures and indicators}

\section{G-index}

Standard criteria were applied to select the CiteSpace analysable records from the downloaded set to generate graphs and obtain indicator values. The records were sub-divided into consecutive 1-year intervals. The papers represented in each separately conducted analysis were selected on the grounds of a g-index value (Egghe, 2006). The g-index is based on the distribution of a set of papers ranked in decreasing order of the number of citations received. The g-index, which divides the set into two groups, is the largest number such that the top $\mathrm{g}$ articles together receive at least $\mathrm{g}^{2}$ citations. The records complying with the modified g-index threshold with a constant, k=5) in every year from 2005 to 2018 were selected for journal and author co-citation analysis. The g-index was defined as the main selection criterion because it determines the largest number of highly cited objects (journals or authors).

\section{Normalisation of co-citation value}

The co-citation values for each yearly interval in each network were normalised using the cosine index (Leydesdorff, 2008b).

\section{Visualisation}

The clusters of co-cited authors and journals for all the years were then re-mixed to form a single network covering the entire period and compute the design. The co-citation networks were represented graphically as nodes (journals and authors) and links. As networks built from bibliographic records may contain many inter-nodal links, leading to saturation or occlusion of the resulting graphic, edges are routinely pruned with tools such as Pathfinder. The result is a network drawn with the minimum number of links required by eliminating all the edges that do not form part of the shortest route between each pair of author or journal nodes (Schvaneveldt; Durso; Dealholt, 1990; White, 2003). Here the networks generated were distributed spatially with the Kamada-Kawai algorithm (Kamada-Kawai, 1989). A timeline was also drawn to represent the Pathfinder network of author co-citation clusters.

\section{Modularity}

Represents the degree to which a network can be broken down into several components or modules. The value denotes the accuracy of network breakdown into clusters (Newman, 2006; Chen; Ibekwe-SanJuan; Hu, 2010).

\section{Silhouette}

Indicates cluster configurational quality: the higher the value, the better the solution (Rousseeuw, 1987).

\section{Betweenness centrality}

Measures the number of shortest paths in a network starting at any node to any other that passes through a given node (Freeman, 1977). A journal or author with high betweenness values act as a relayer or nexer. Their significance lies in their ability to relate clusters of authors comprising schools or approaches within a speciality at any given time or who are cited by heterogenous sets of co-citation clusters. 


\section{Burst}

is a strength indicator based on the frequency or intensity of significant attention received by a given author or journal in a short period of time. It is calculated relative to a similar moment in a given cycle (Mane; Börner, 2004) and measures citation-based impact. Papers with high burst values acquire landmark status, for they attract intense research community attention and identify the dates involved. Kleinberg's (2002) algorithm was used to calculate burst values.

\section{Sigma}

Is a metric that combines the values of betweenness, a structural measure, and burst, or peer recognition as described above (Chen; Ibekwe-SanJuan; Hu, 2010).

\subsection{Author cluster labelling and subject description}

Nominal syntagmas were retrieved from the titles of the articles cited in each cluster to label author clusters. Here the statistical method known as the log-likelihood ratio (LLR) was used to specify labels. The general description of the subjects addressed by the articles citing each cluster was established with latent semantic indexing (Deerwester et al., 1990) based on the terms in the titles of the citing papers.

\section{Results}

\subsection{Raw statistical data}

The 8145 records downloaded from Dimensions included

- 5417 articles

- 1894 book chapters

- 362 proceedings

- 249 books and

- 57 preprints or eprints.

Pre-prints are understood to be non-peer reviewed versions of scientific or academic papers. The total number of documents grew steadily from 2005 to 2018, with a dip in 2015 (Figure 1). Compound yearly growth from 2012, when the rate began to spike, to 2018 was $29 \%$.

After reorganisation in October 2019, Dimensions' hierarchical subject classification (Bode et al., 2018) consisted in 22 divisions and 157 fields of research. The 10 fields of research with the highest output identified for the downloaded records and the 10 most prevalent sources are

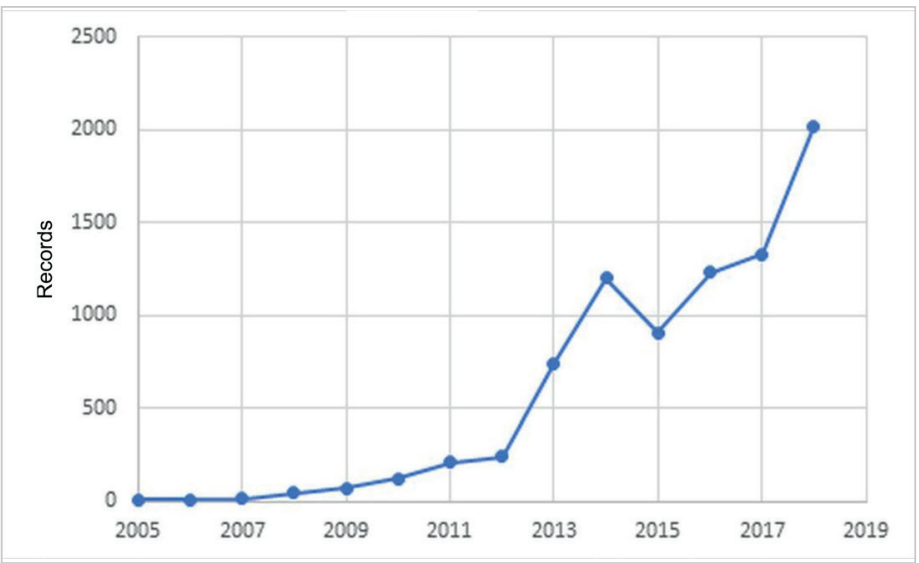

Figure 1. Number of records, 2005-2018, retrieved from Dimensions with the statement altmetric OR altmetrics OR science $2.0 \mathrm{OR}$ article level metrics OR social media metrics listed in Table 1.

The fields of research to which the studies were allocated, as denominated in Dimensions, stand as proof of subject clustering in the field. Information Systems was observed to be the predominant field. A related field, Artificial Intelligence and Image Processing, ranked fifth, an indication that information systems are particularly relevant to the speciality. The other subject fields with which the speciality was observed to be related included medicine (Public Health \& Health Services) and a wide range of social sciences.

Table 1. Ten most productive fields of research (Dimensions, 2005-2018)

\begin{tabular}{|l|c|l|l|}
\hline \multicolumn{1}{|c|}{ Field of research } & No & \multicolumn{1}{c|}{ Source } \\
\hline Information systems & 1.078 & Nature & 318 \\
\hline Public health \& health services & 453 & Scientometrics & 211 \\
\hline Sociology & 386 & Lectures notes in computer science \\
\hline Psychology & 276 & Jasist \\
\hline Artificial intelligence and image processing & 241 & Journal of informetrics \\
\hline Policy and administration & 222 & PLoS one & $\mathbf{8 2}$ \\
\hline Applied economics & 174 & Communication in computer and information science \\
\hline Specialist studies in education & 153 & New England journal of medicine \\
\hline Business and management & 138 & Learned publishing \\
\hline Historical studies & 135 & Neurology & 52 \\
\hline
\end{tabular}


The list of journals with the highest output in the speciality contained three titles on metrics research pivotal to information sciences studies:

Scientometrics, Journal of informetrics, and Journal of the Association of Information Science and Technology (Jasist).

Learned publishing, carrying primarily to articles on academic communication and professional particulars of academic publishing, was also found to be a significant source of papers dealing with the speciality.

Dimensions delivers information on the impact of the documents retrieved from its article database. Table 2 gives some of the raw data on the articles downloaded. The row headed 'Document citations' refers to the number of times one paper was cited by another in Dimensions. Citations appeared in all manner of documents, not only articles but also books, book chapters, monographs, conference papers and pre-prints. As a standard measure of a study's impact, citations constitute the most widely used indicator of research community acceptance / recognition of published works. 'Citations per document', in turn, is an aggregate indicator, calculated by dividing the total number of citations by the total number of documents.

Table 2. Summary of raw data on impact of the records downloaded (2010-2018)*

\begin{tabular}{|c|c|c|c|c|c|c|c|c|c|c|}
\hline & 2010 & 2011 & 2012 & 2013 & 2014 & 2015 & 2016 & 2017 & 2018 & $\%$ \\
\hline Documents & 120 & 210 & 243 & 741 & 1200 & 905 & 1229 & 1328 & 2022 & \\
\hline Document citations & 651 & 954 & 1314 & 1948 & 2758 & 4453 & 6976 & 10832 & 18535 & \\
\hline$\%$ Documents cited & 71.70 & 72.40 & 67.10 & 42.90 & 37.20 & 59.40 & 54.60 & 50.20 & 24.40 & 44.40 \\
\hline$\%$ Documents not cited & 28.30 & 27.60 & 32.90 & 57.10 & 62.80 & 40.60 & 45.40 & 49.80 & 75.60 & 55.60 \\
\hline$\%$ Citations per document & 9.86 & 17.09 & 12.59 & 8.57 & 5.19 & 7.22 & 6.67 & 5.83 & 1.06 & 6.59 \\
\hline
\end{tabular}

*Data for the period 2005-2009 were not available in Dimensions on the date of the query

\subsection{Journal co-citation analysis}

The full set of 8145 bibliographic records downloaded from Dimensions was processed and visualised with CiteSpace to analyse journal co-citation. The modified g-index $(\mathrm{g}=5)$ reduced the number to 3974 records. The 30227 bibliographic references listed in those records were used to generate a co-citation network of 355 nodes and 1095 links.

The merged networks created with CiteSpace contained the most prominent journals publishing articles on the speciality and their interconnections (Figure 2). The titles of journals or academic publications with over 150 citations are shown in connection with the nodes, while the size of the latter is proportional to the number of citations.

- PLoS one (1043)

- Journal of the Association for Information Science and Technology (1036)

- Nature (989)

- Scientometrics (872)

- Science (858)

were found to predominate.

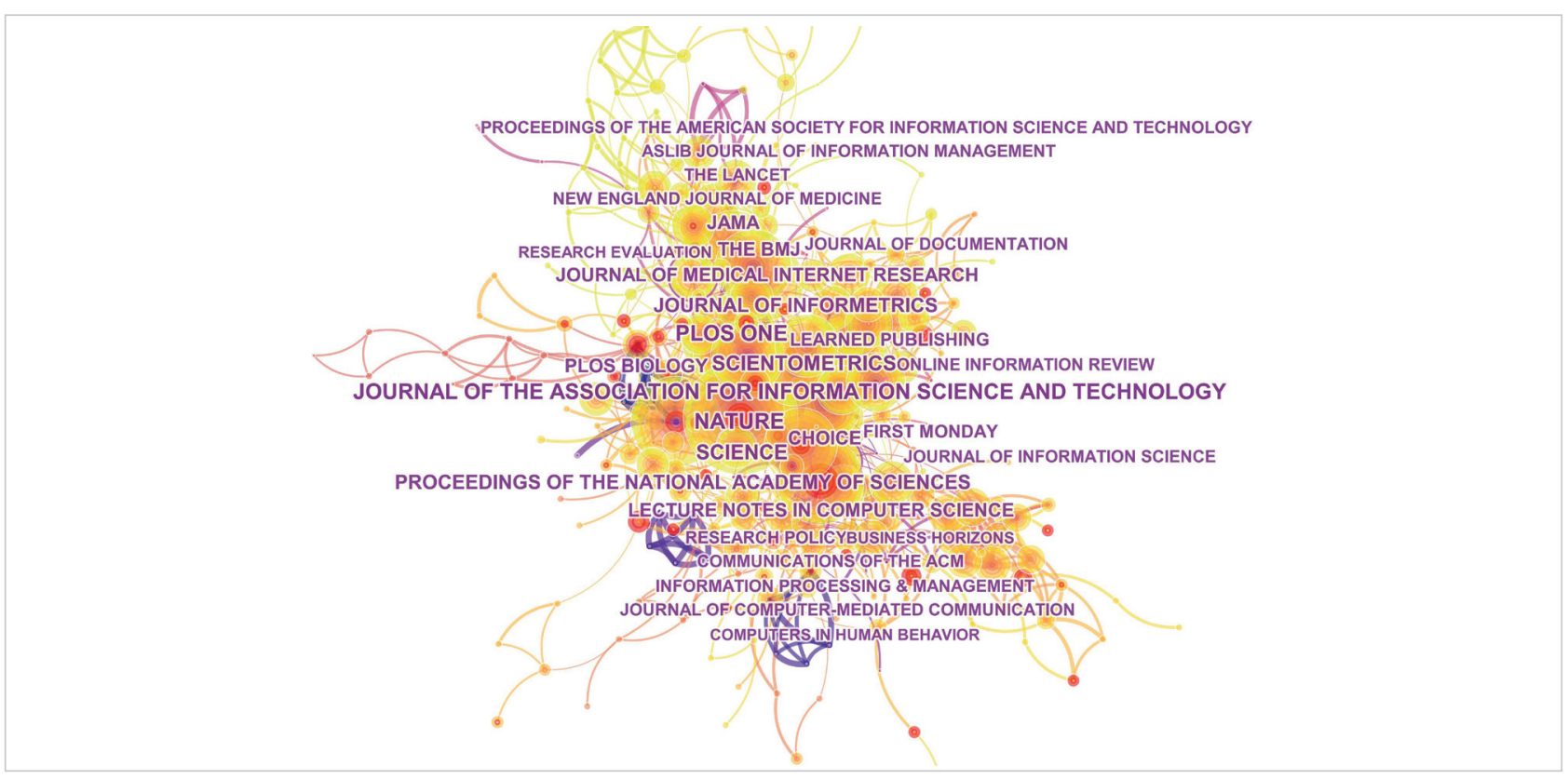

Figure 2. Co-citation network of alternative metrics journals, 2005-2018; size of node labels proportional to number of citations (threshold: $\geq 150$ citations). Source: Dimensions 
The larger a node, the greater the significance of the respective periodical base for researchers engaging in the speciality. A red ring around a node denotes the presence of significant bursts. Link colours refer to the networks generated in each interval. The older intervals (2005-2009) are shown in shades of violet and the more recent (2013-2018) of orange and yellow.

Table 3 lists the top 39 titles resulting from the journal co-citation analysis and the number of times each was cited. Many of the journals with values in the 'Citation' column are related to:

- Information Sciences (Jasist, Learned publishing, Journal of documentation...),

- Informetrics (Scientometrics, Journal of informetrics...),

- Science and technology assessment policies (Research policy, Research evaluation...),

- Multi-disciplinary research (PLoS one, Nature, Science, Proceedings of the National Academy of Sciences),

- Medicine (The Lancet, Journal of medical research, Journal of the American Medical Association...),

- Computer Sciences (Lecture notes in computer science, Communications of the ACM...).

Table 3. Top 39 journals: Pathfinder network of co-cited alternative metrics journals, 2005-2018

\begin{tabular}{|c|c|c|c|c|}
\hline Rank & Journal & No. citations & Burst & Centrality \\
\hline 1 & PLoS one & 1043 & & 0.08 \\
\hline 2 & Journal of the Association for Information Science and Technology & 1036 & & 0.08 \\
\hline 3 & Nature & 989 & 9.50 & 0.19 \\
\hline 4 & Scientometrics & 872 & & 0.06 \\
\hline 5 & Science & 858 & 20.30 & 0.06 \\
\hline 6 & Journal of informetrics & 546 & & 0.03 \\
\hline 7 & Proceedings of the National Academy of Sciences & 536 & & 0.08 \\
\hline 8 & Journal of medical internet research & 398 & & 0.19 \\
\hline 9 & The BMJ & 394 & & 0.10 \\
\hline 10 & Jama & 393 & & 0.05 \\
\hline 11 & Lecture notes in computer science & 380 & 20.20 & 0.17 \\
\hline 12 & PloS biology & 348 & & 0.12 \\
\hline 13 & Choice & 345 & & 0.14 \\
\hline 14 & Learned publishing & 321 & & 0.09 \\
\hline 15 & First Monday & 313 & & 0.10 \\
\hline 16 & New England journal of medicine & 243 & & 0.08 \\
\hline 17 & Journal of documentation & 229 & & 0.01 \\
\hline 18 & Research policy & 226 & & 0.02 \\
\hline 19 & Communications of the ACM & 220 & 18.50 & 0.07 \\
\hline 20 & Information processing \& management & 219 & 2.97 & 0.15 \\
\hline 21 & Journal of information science & 218 & & 0.04 \\
\hline 22 & Online information review & 192 & & 0.09 \\
\hline 23 & The lancet & 191 & & 0.01 \\
\hline 24 & Aslib journal of information management & 190 & & 0.04 \\
\hline 25 & Journal of computer-mediated communication & 185 & & 0.11 \\
\hline 26 & Proceedings of the American Society for Information Science and Technology & 179 & & 0.04 \\
\hline 27 & Business horizons & 174 & & 0.09 \\
\hline 28 & Computers in human behavior & 174 & & 0.02 \\
\hline 29 & Research evaluation & 164 & & 0.01 \\
\hline 30 & Plos medicine & 153 & & 0.21 \\
\hline 31 & Annual review of information science and technology & 152 & & 0.03 \\
\hline 32 & College \& research libraries & 147 & & 0.06 \\
\hline 33 & Bulletin of the Association for Information Science and Technology & 146 & 2.85 & 0.07 \\
\hline 34 & Journal of marketing & 141 & & 0.06 \\
\hline 35 & Serials review & 140 & & 0.06 \\
\hline 36 & Journal of interactive marketing & 140 & & \\
\hline 37 & Journal of marketing research & 131 & & 0.01 \\
\hline 38 & The journal of academic librarianship & 125 & & 0.06 \\
\hline 39 & El profesional de la información & 121 & 12.30 & \\
\hline
\end{tabular}


Journal co-citation networks (Figure 2) show the structure of research specialities based on the literature published while also generating information useful for identifying the periodicals pivotal to specific research-geared groups (McCain, 1991). The Pathfinder network builds microstructures that are more legible than graphs in which the links have not been pruned, for they are necessarily simplified representations of the speciality analysed (Figure 3). The internodal links in such networks are more readily perceptible and more meaningful for establishing internodal connections. When links are deleted, the betweenness values rise and the journals positioned at the centre of the speciality are easier to identify. After pruning eliminated $28 \%$ of the original links from the initial graph, the network was visually clearer.

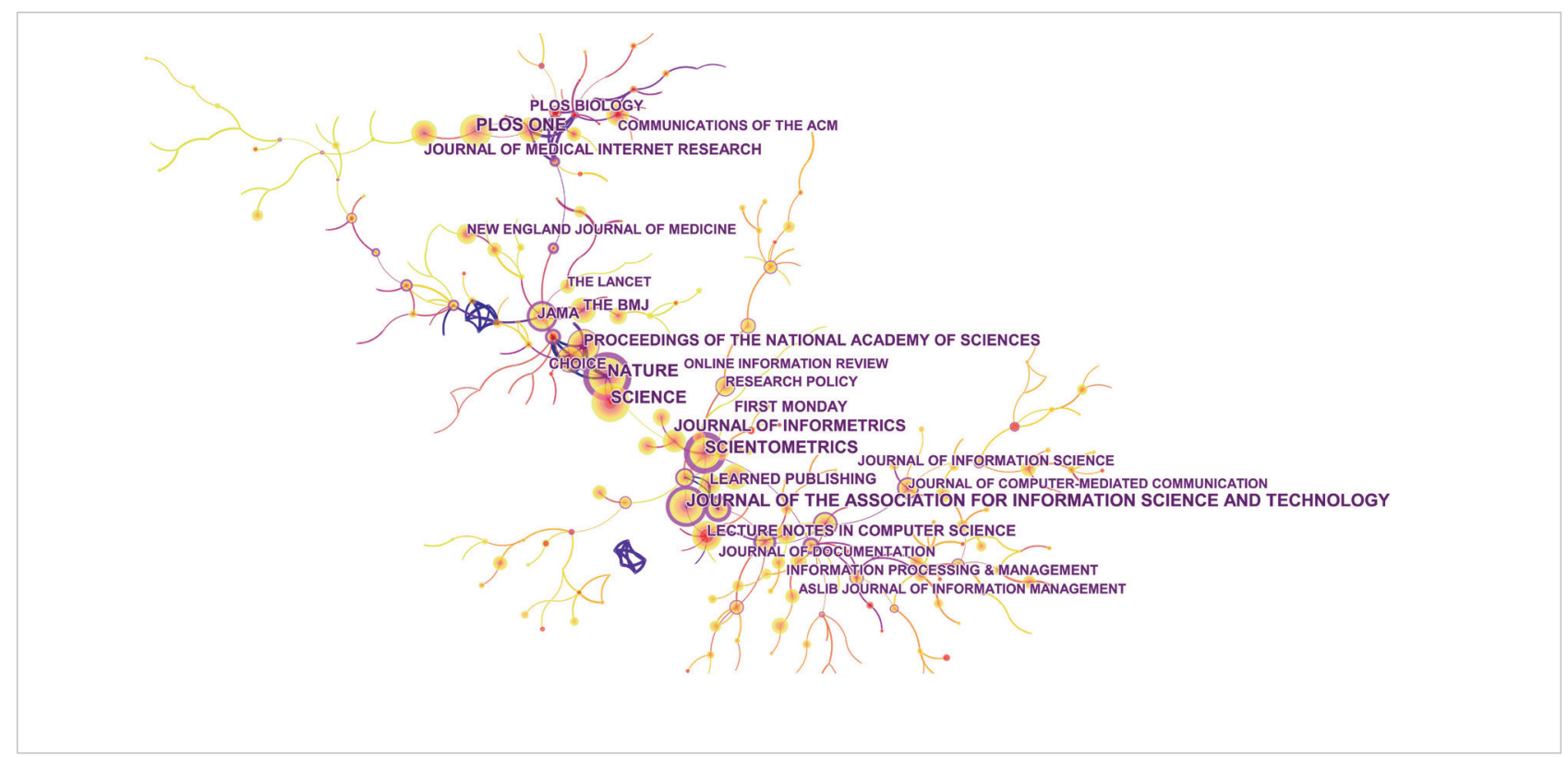

Figure 3. Pathfinder network of co-cited alternative metrics journals, 2005-2018; size of node labels proportional to number of citations (threshold: $\geq 150$ citations). Source: Dimensions

The size of the nodes was proportional to the number of citations received. The presence of fuchsia rings denotes high betweenness values, such as observed for Scientometrics (1.12), Nature (1.02), Jasist (0.77), Journal of documentation (0.65), Journal of the American Medical Association (0.53), and Cell (0.51). The yellow interior shown in most of the circles means that the cumulative citations were received very recently.

The speciality's intellectual fundamentals were found in studies published in reputed information and documentation journals and multi-disciplinary periodicals. The former are located on the dense lower part of the graph. Of particular prominence were journals publishing quantitative studies on science such as Journal of the Association for Information Science and Technology, Scientometrics and Journal of informetrics, along with others such as Learned publishing, which specialises in academic communication and publishing. Journals geared to computer technology-based communication (Journal of computer-mediated communication) together with three relating to information and documentation theory and methods (Information processing and management, Journal of documentation and Journal of information science) were also identified. Two journals analysing new IT developments, Lecture notes in computer science and Communications of the ACM, which may carry related technical articles, are also present on the graph.

The multi-faceted nature of altmetrics can be gleaned from the inclusion on the co-citation graph of multi-disciplinary journals such as Science, Nature, Proceedings of the National Academy of Sciences and PLoS one, along with many medical journals. A series of medical journals appear in the upper part of the graph, above Choice, a periodical published by the Association of College and Research Libraries: Journal of the American Medical Association (JAMA), The lancet, British medical journal (BMJ), New England journal of medicine, Journal of medical internet research, and PLoS biology.

The presence of such journals is very likely due to the biomedical community's intense use of social networking and its impact on professional practice, and its researchers' tendency to choose journals to publish papers with high altmetric impact.

\subsection{Author co-citation analysis}

An author co-citation network detects those who may be deemed experts or key authors in the speciality's knowledge base. The g-index $(g=5)$ criterion applied reduced the number of records to 3974 and of references to 56936 . The resulting network has 284 nodes and 1453 links. A substantial $86 \%$ of the nodes are interlinked, forming a large component. The authors with the highest values of the various indicators are listed in Table 4. 
Table 4. Top authors* in author co-citation networks, all years

\begin{tabular}{|c|c|c|c|c|c|c|c|}
\hline Citation & Value & Burst & Value & Betweenness & Value & Sigma & Value \\
\hline Thelwall, M. & 504 & Shneiderman, B. & 30.60 & Garfield, E. & 0.77 & Jacsó, P. & 92.90 \\
\hline Bornmann, L. & 376 & Waldrop, M. M. & 15.20 & Jacsó, P. & 0.71 & Shneiderman, B. & 37.40 \\
\hline Haustein, S. & 334 & Gloor, P. A. & 14.00 & Cronin, B. & 0.70 & Butler, D. & 20.90 \\
\hline Eysenbach, G. & 314 & Wasserman, S. & 12.30 & Meho, L. I. & 0.69 & Vaughan, L. & 6.14 \\
\hline Priem, J. & 263 & Neylon, C. & 11.80 & Kousha, K. & 0.55 & Gloor, P. A. & 4.88 \\
\hline Garfield, E. & 234 & Priem, J. & 10.20 & Butler, D. & 0.48 & Wasserman, S. & 3.36 \\
\hline Hirsch, J. E. & 203 & Aguillo, I. F. & 9.48 & Eysenbach, G. & 0.48 & Brody, $\mathrm{T}$. & 3.35 \\
\hline Costas, R. & 200 & Kozinets, R. V. & 8.97 & Vaughan, L. & 0.43 & Kozinets, R. V. & 2.72 \\
\hline Van-Noorden, R. & 183 & Bollen, J. & 8.71 & Bradley, J. & 0.42 & Neylon, C. & 2.58 \\
\hline Piwowar, $\mathrm{H}$. & 174 & Kietzmann, J. H. & 8.66 & $\mathrm{Li}, \mathrm{X}$. & 0.39 & Priem, J. & 2.51 \\
\hline Bollen, J. & 164 & Zitt, M. & 8.66 & Brody, T. & 0.37 & Kaplan, A. M. & 2.23 \\
\hline Moed, H. F. & 155 & Harnad, S. & 8.59 & Gruzd, A. & 0.35 & Piwowar, H. A. & 2.11 \\
\hline Mohammadi, E. & 153 & Jacsó, P. & 8.45 & Mas-Bleda, A. & 0.33 & Waldrop, M. M. & 2.05 \\
\hline & & & & Giles, J. & 0.24 & Shuai, X. & 1.65 \\
\hline & & & & Hoffmann, R. & 0.24 & Torres-Salinas, D. & 1.40 \\
\hline & & & & Haustein, S. & 0.22 & & \\
\hline & & & & Newman, M. E. J. & 0.22 & & \\
\hline & & & & Lin, J. & 0.21 & & \\
\hline
\end{tabular}

*Only first author cited

The Pathfinder author co-citation network was broken down into 37 clusters to approximate the lines of research. That breakdown yielded an overall modularity value of $Q=0.885$, i.e., the degree to which the network can be broken down into smaller components or modules. A high modularity value indicates that the network is reasonably well divided and not liable to further clustering. Of the 284 authors initially comprising the network, 246 (86 \%) were included in a co-citation cluster. The silhouette value, in turn, at a mean value of 0.554 , denoted good cluster configuration quality.

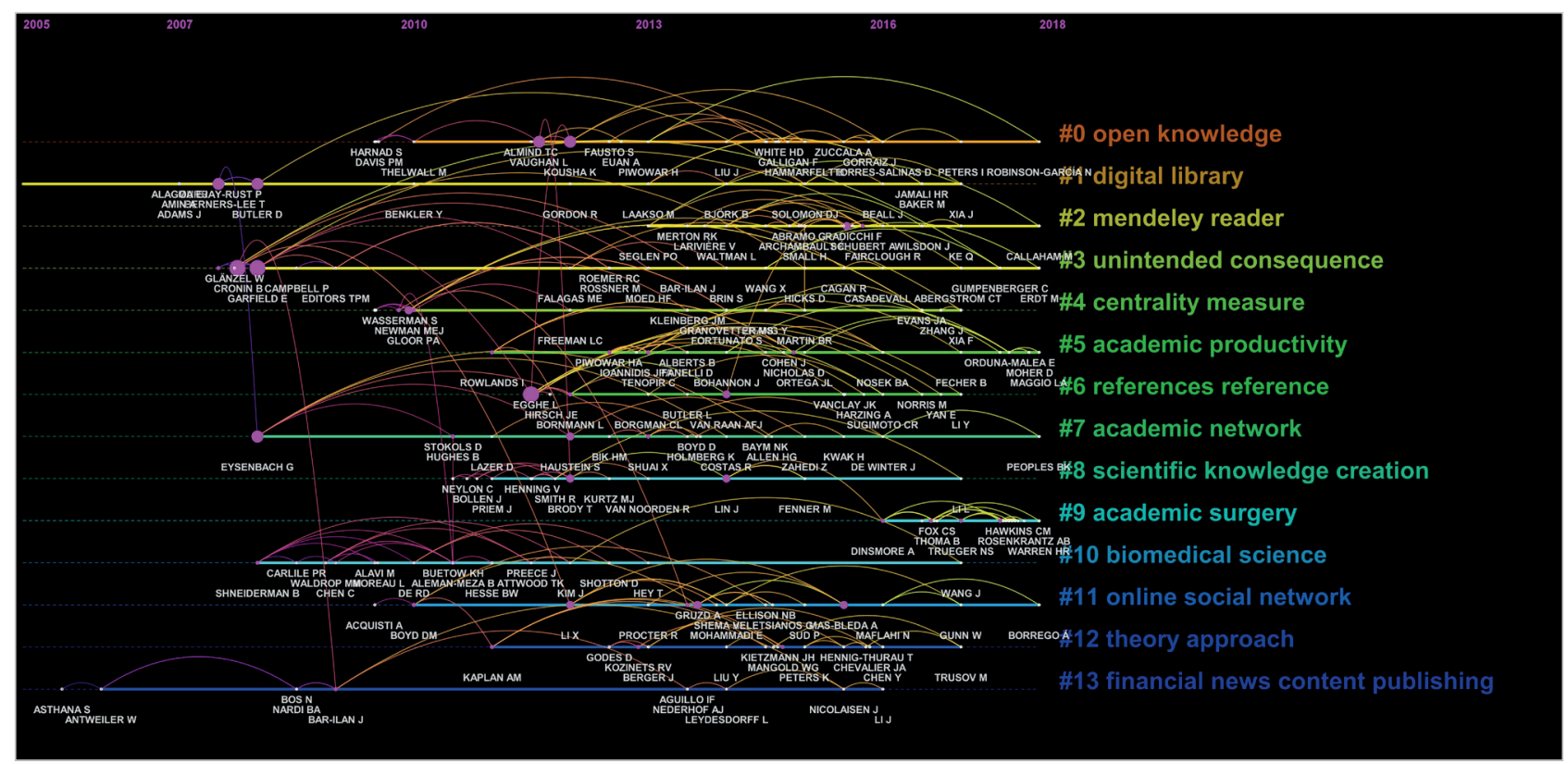

Figure 4. Timelines for alternative metrics author co-citation clusters (2005-2018). Source: Dimensions

The timelines in Figure 4 are ranked by descending order of size of the co-cited clusters. The label on the right summarises the general context in which each cluster was cited. Cluster \#4, centrality measures, for instance, means that the cluster of co-cited papers was cited in articles by significant authors studying centrality measures. The authors comprising each co-citation cluster are listed below the respective line. The nodes with the highest betweenness values in each line are shown in fuchsia. The position on the timeline dates the documents in keeping with the scale at the top of the graph. The duration over time of each cluster is represented by the length of the line. Cluster \#9, for instance, began in 2016 and remained active in 2018, whereas \#8, \#10,\#12 and \#13 were no longer active in the latter year. Only $50 \%$ of the clusters represented were active in 2018: \#0, \#2, \#5, \#7, \#9 and \#11. 
In five clusters (\#1, \#13,\#10,\#3 and \#8) the mean dates (2010-2012) denoted older articles. Six (\#0, \#4, \#7, \#6, \#11, and \#12) were dated in 2013 and 2014 and only three (\#2, \#5 and \#9) more recently (2015 and 2017).

In the Pathfinder network of co-cited authors in Figure 5, the label for each cluster refers to the citing articles. The clusters have associated colors that identify the average year of constitution, with yellow for the more recent and ochre and pink for the older.

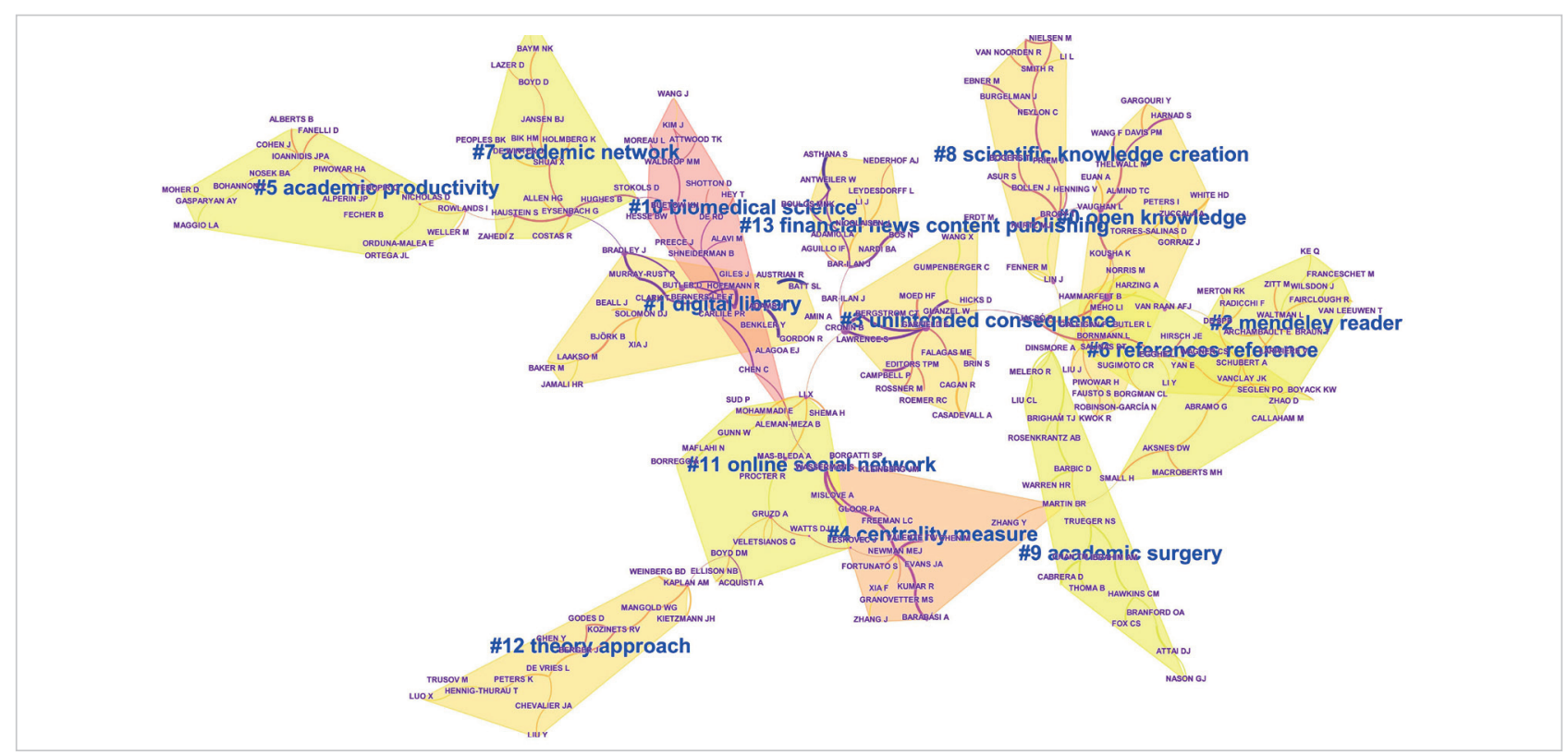

Figure 5. Pathfinder network for 284 authors representing co-citation patterns for documents with a g-index value of 5, 2005 to 2018. Source: Dimensions.

The three syntagmas selected on the grounds of the context of the citing articles by applying the log-likelihood ratio to their titles are listed in Table 5, which also gives the size in number of documents and mean date of publication of the co-cited clusters. That provides an approximation of the age of each. The silhouette measures cluster uniformity. The values of near one in all cases infer that the clusters can be validly interpreted and the division into clusters is consistent, suggesting that the sets associated with these clusters are approximately in line with the speciality.

The sets in these clusters are approximately aligned with speciality subdivision

Table 5. Summary of the largest clusters of co-cited documents on alternative metrics based on the Pathfinder author co-citation network (2005-2018)

\begin{tabular}{|c|c|c|c|c|}
\hline ID No & Size & Silhouette & Year & Top three syntagmas for citing articles determined with the log-likelihood ratio \\
\hline 0 & 22 & 0.983 & 2013 & open knowledge; altmetrics collection; web indicator \\
\hline 1 & 22 & 0.964 & 2010 & digital library; next generation web; bibliographic tool \\
\hline 2 & 20 & 0.985 & 2015 & Mendeley reader; adverse effect; assessing research \\
\hline 3 & 19 & 0.970 & 2012 & unintended consequence; journal rank; ResearchGate score \\
\hline 4 & 18 & 0.927 & 2013 & centrality measure; social network; blog-supported scientific communication \\
\hline 5 & 18 & 0.938 & 2015 & academic productivity; using publication metrics; open data citation advantage \\
\hline 6 & 17 & 0.957 & 2014 & references reference; bibliometric indicator; Google Scholar author citation \\
\hline 7 & 17 & 1.000 & 2013 & academic network; share data; using science \\
\hline 8 & 17 & 1.000 & 2012 & scientific knowledge creation; exploring researchers opinion; scholarly communication \\
\hline 9 & 17 & 0.975 & 2017 & academic surgery; academic tweet; leveraging Twitter \\
\hline 10 & 16 & 0.923 & 2011 & biomedical science; engaging community intelligence; accelerating scientists knowledge \\
\hline 11 & 16 & 0.892 & 2014 & online social network; Mendeley readership count; applying social network analysis \\
\hline 12 & 15 & 1.000 & 2014 & theory approach; social media maturity model; social media metrics \\
\hline 13 & 12 & 0.986 & 2010 & financial news content publishing; internet message board; market behaviour \\
\hline
\end{tabular}

The largest and oldest cluster, with 2010 as the mean year of publication, was \#1, digital library. It had 22 references and a silhouette of 0.964 , suggestive of high intra-cluster uniformity. The link between the citing and cited documents can be measured as the percentage of the former that cite the latter. Four citing papers in cluster \#1 cited $14 \%$ or more of all the references in the cluster (Table 6). The article with higher coverage (27\%) reviewed the ways to retrieve scientific 
information from specialised libraries and bibliographic databases. It also described services such as Zotero, Mendeley and CiteULike, deemed to be intrinsic to Science 2.0 (Hull; Pettifer; Hell, 2008). The general subjects forming the cluster on new Web 2.0 tools were identified by retrieving terms such as open access, references, sharing scholarship and open access uptake from the titles using latent semantic indexing.

Table 6. Main citing articles for cluster \#1

\begin{tabular}{|c|l|}
\hline Fraction cited & \multicolumn{1}{c|}{ Citing articles*, cluster \#1 } \\
\hline 0.27 & Hull, Duncan (2008). “Defrosting the digital library: bibliographic tools for the next generation web” \\
\hline 0.14 & Bailey, David (2008). “Drug discovery in the era of Facebook-new tools for scientific networking” \\
\hline 0.14 & Hoffmann, Robert (2008). "A wiki for the life sciences where authorship matters" \\
\hline 0.14 & Hua, Fang (2017). "Open access: concepts, findings, and recommendations for stakeholders in dentistry" \\
\hline
\end{tabular}

*Only first author cited

In a similar vein, the citing articles for the second largest cluster, \#0, open knowledge, contained 22 references and a very high silhouette value (0.983), denoting consistency in the constituent items. The mean year of publication was 2013. Table 7 lists the citing articles with the highest percentage of citations of papers in the cluster.

Table 7. Main citing articles for cluster \#0

\begin{tabular}{|c|l|}
\hline Fraction cited & \multicolumn{1}{c|}{ Citing articles*, cluster \#0 } \\
\hline 0.18 & García-Peñalvo, Francisco (2010). “Open knowledge: challenges and facts" \\
\hline 0.14 & Barnes, Cameron (2015). "The use of altmetrics as a tool for measuring research impact” \\
\hline 0.14 & Kousha, Kayvan (2016). “Can Amazon.com reviews help to assess the wider impacts of books?" \\
\hline 0.14 & Priem, Jason (2012). “The altmetrics collection” \\
\hline 0.14 & Thelwall, Mike (2012). "A history of webometrics" \\
\hline 0.14 & Todeschini, Roberto (2016). "Handbook of bibliometric indicators" \\
\hline 0.14 & Zhou, Qingqing (2016). "Measuring book impact based on the multi-granularity online review mining” \\
\hline
\end{tabular}

*Only first author cited

Applying latent semantic indexing to the titles of the articles in cluster $\# 0$ associated the cluster with the subjects altmetrics, open data citations advantage, humanities, measuring research impact, and changing landscape.

Clusters \#2, \#5 and \#9 contained the most recent documents. The mean date of the 20 articles in cluster \#2 was 2015. Its silhouette value, at 0.985 , was the second highest (Table 5). The citing article with the highest co-citation percentage, authored by Fairclough (2015), advocated for the use of Mendeley data to compare impact values nationally. This cluster was recently formed, as the general graph is Figure 4 shows.

Table 8. Main citing articles for cluster \#2

\begin{tabular}{|c|l|}
\hline Fraction cited & \multicolumn{1}{c|}{ Citing articles*, cluster \#2 } \\
\hline 0.30 & Fairclough, Ruth (2015). "National research impact indicators from Mendeley readers" \\
\hline 0.25 & $\begin{array}{l}\text { Thelwall, Mike (2016). "The discretised lognormal and hooked power law distributions for complete citation data: best } \\
\text { options for modelling and regression" }\end{array}$ \\
\hline 0.20 & $\begin{array}{l}\text { Bornmann, Lutz (2016). "Normalization of Mendeley reader impact on the reader- and paper-side: a comparison of the } \\
\text { mean discipline normalized reader score (mdnrs) with the mean normalized reader score (mnrs) and bare reader counts" }\end{array}$ \\
\hline 0.20 & Thelwall, Mike (2015). "Geometric journal impact factors correcting for individual highly cited articles" \\
\hline
\end{tabular}

* Only first author cited

The subjects addressed in the cluster related alternative metrics to their validity and impact on research. The terms most often retrieved from the titles of the articles using latent semantic indexing included citations, altmetrics data, validity and impact research.

Cluster \#5, academic productivity, had a mean date of 2015, 18 documents and a very high silhouette value, 0.938 . Three of the citing papers listed in Table 9 cited over $15 \%$ of all the references in the cluster. Application of latent semantic indexing to the titles of the papers showed the subjects generally discussed in this cluster to include altmetrics, correlating altmetrics, research, education and university. 
Table 9. Main citing articles for cluster \#5

\begin{tabular}{|c|l|}
\hline Fraction cited & \multicolumn{1}{c|}{ Citing articles*, cluster \#5 } \\
\hline 0.17 & Gasparyan, Armen-Yuri (2018). "Researcher and author impact metrics: variety, value, and context" \\
\hline 0.17 & Piwowar, Heather A. (2013). "Data reuse and the open data citation advantage" \\
\hline 0.17 & Carpenter, Christopher R. (2014). “Using publication metrics to highlight academic productivity and research impact" \\
\hline 0.11 & Koltay, Tibor (2015). "The shift of information literacy towards research 2.0" \\
\hline
\end{tabular}

* Only first author cited

Cluster \#9 (Table 10), the most recently constituted (2017), had a high silhouette value (0.975) and comprised 17 papers, all published in medical journals. The papers with the highest citation percentage, all over $23 \%$, are listed in the table.

Table 10. Main citing articles for cluster \#9

\begin{tabular}{|c|l|}
\hline Fraction cited & \multicolumn{1}{c|}{ Citing articles*, cluster \#9 } \\
\hline 0.35 & Logghe, Heather J. (2018). "The academic tweet: Twitter as a tool to advance academic surgery" \\
\hline 0.29 & Kalia, Vivek (2018). “Leveraging Twitter to maximize the radiology meeting experience” \\
\hline 0.24 & Bundy, Jacob J. (2018.) “\#radiology: A 7-year analysis of radiology-associated hashtags" \\
\hline 0.24 & Colbert, Gates B. (2018). "The social media revolution in nephrology education” \\
\hline 0.24 & Hage, Anthony N. (2018). "\#interventionalradiology" \\
\hline 0.24 & $\begin{array}{l}\text { Rosenkrantz, Andrew B. (2017). "Alternative metrics ('altmetrics') for assessing article impact in popular general radiolo- } \\
\text { gy journals" }\end{array}$ \\
\hline
\end{tabular}

* Only first author cited

The term Twitter appeared in two of the six articles in the table. The subjects found to characterise the cluster, further to latent semantic indexing, included social media, scientists, digital methods, cyber-enabled research, Twitter, and randomized trial.

\section{Discussion}

Scientific specialities are intellectual micro-environments built by researchers engaging in a discipline who share interests in certain lines of research. Those concerned share subject matter, theories, approaches and data analysis techniques and attend the same scientific congresses and meetings (Whitley, 2000; Morris; Van-der-Veer-Martens, 2008).

The general consensus in place since the nineteen sixties is that the scientific literature published in peer-reviewed journals is a valid data source for the study of scientific specialities. A key element in that consensus is a given study's citation-mediated relationships to those preceding it and others that will follow. The links deriving from formal communication relationships that interconnect scientists underlie the establishment of conceits about specialities. The analysis and visualisation of such relationships are the tools for charting maps of specialities into which scientific disciplines and areas of research are subdivided. The passage of time makes it possible to model and detect such subdivisions, observe their development and structure, determine the intensity of attention aroused in the respective scientific community and track their possible demise due to a decline Conceits about specialities depend on formal communication inter-relationships in earlier interest (Yan; Ding, 2012).

Alternative metrics constitute an area of growing research community, as attested to by the data on scientific output (Figure 1). The recent appearance of the pursuit may explain why it is not explicitly shown on most recent library and information science maps (Chang; Huang; Lin, 2015; Yang et al., 2016; Hou; Yang; Chen, 2018; Liu; Yang, 2019), and why the term 'altmetrics' is not one of the area's most prominent keywords (Onyancha, 2018). The study of its intellectual relationship and subsequent development therefore holds dual interest, for its status as a recently birthed and growing microstructure.

The journal co-citation maps generated here represent the structure of the speciality at that level of disaggregation. The choice is justified by the fact that scientific intellectual development and organisation, as well as the growth of new specialities and disciplines, are recorded and validated in academic journals (Leydesdorff, 2008a). The resulting structures can be applied to arrange and improve the efficiency of searches for new information. For instance, betweenness centrality values can be used to identify the multi-disciplinary journals engaging in a recent speciality (Leydesdorff; Wagner; Bornmann, 2018), while burst values further hierarchise journals based on the abrupt rise in attention received by certain specific documents in a short period of time. Obviously, however, not all journals can be scored on the grounds of that indicator. 
In any research speciality groups of authors and colleagues can be found who aspire to make significant contributions to secure repute and rewards. The dynamics inevitably generated involve cooperation and mutual dependence. Whitley reflected on the existence of what he called the 'degree of functional dependence' between scientists, referring to the use made of fellow specialists' results, ideas and procedures to generate knowledge deemed as useful and competent contributions (Whitley, 2000). Tables 4-10, summarising the author co-citation analyses conducted, reveal which authors are significant and intellectually esteemed and recognised by others engaging in the speciality, thereby guiding the direction of research. Those results are deemed here to validate the construct.

The primary aim of this analysis lies in defining the intellectual core of the research speciality addressed. With the bibliometric procedures used, $48 \%$ of the records comprising the entire initial dataset met the $\mathrm{g}=5 \mathrm{criterion}$. The author co-citation network built contained $3.4 \%$ of the original records and $7.1 \%$ of the total records in the g=5 document subset. After cluster analysis (Table 5), the number of documents comprising the speciality accounted for $2.5 \%$ of the documents initially downloaded and $5.1 \%$ of the ones meeting the g=5 criterion. The results delivered by automatic procedures proved, then, to be highly selective and significant. Preliminary manual selection as a method for obtaining a full, clean dataset, in addition to being inevitably subjective and biased, fails to deliver results able to compensate for the overwhelmingly high costs involved (Zhao, 2009).

That authors such as J. E. Hirsch, H. F. Moed or E. Garfield appear in the results may initially seem surprising. Whilst Hirsch, for instance, has no individual output in altmetrics, he was identified as a prominent author in the speciality, in all likelihood due to the great impact of his indicator and its application in altmetric papers. While dynamic, young specialities are in debt to other more mature specialities with a broader spectrum of approaches, a longer track record and a larger pool of resources. Some alternative metrics researchers have been known to previously engage in other specialities. Their presence in this analysis stands as proof that altmetrics is an intellectual field bounded by assessment bibliometrics, in particular by studies geared to measuring research impact and impactful research, which are also cited in papers on alternative metrics.

A new discipline may, in its early years, develop a number of lines of inquiry that may then be judged inaccurate or unsuitable and discontinued or eclipsed by others. It may also import methods, theories or common interests, as noted above, which at a later stage of maturity might be forthcoming within the speciality itself. This analysis detected 14 author co-citation clusters in the period. Half of those were no longer active in 2018 and very few inter-cluster connections were observed (Figure 4).

Research specialities are differentiated internally into segments or lines of research, which in cognitive terms would express micro-scale divisions of knowledge (Becher, 1989). Neither is their duration stable (Table 5) nor can they be readily established as clearly as the speciality studied here, in which very high silhouette values for cluster differentiation were delivered by author co-citation analysis. The picture painted is a speciality with a highly fragmented structure, perhaps due to today's demands on scientists to publish documents that make very specific contributions. The inference therefore is that it is a fairly young, developing and yet to be consolidated discipline.

Refining the analytical granularity to the article level (Tables 5-10) afforded a more detailed and specific understanding of the speciality's structure. Articles are the element that best represents the intellectual structure of scientific specialities today (Waltman; Van-Eck, 2012). In this case they revealed the greater freedom and flexibility with which scientists establish a cognitive base for their research, as is the norm in social science (Fanelli; Glänzel, 2013).

\section{Limitations to this study}

This research is subject to limitations. Whereas the local science maps generated were charted by retrieving a set of records with a given search statement, other selection procedures might be envisaged. A series of key authors in the speciality could have been selected, for instance, and a snowball procedure deployed to retrieve documents related to those authors' research. The boundaries of altmetrics have not, then, been definitively drawn with the method followed.

Users presently have a wide range of international bibliographic databases to choose from. Traditional bases such as Web of Science, Scopus and Google Scholar are now competing with Microsoft Academic, Dimensions, Crossref and others. As the base selected for this study is one of the most recent, its content may be unstable and subject to internal adjustments. Data must be furnished, for instance, to trigger its machine learning models. At the same time, however, it chosen indexes the full text of documents and books and uses artificial intelligence-driven machine learning techniques to link and integrate resources from different origins (Bode et al., 2018). Those novel features prompted the choice. The study drew from both the performance and precision of the automatic retrieval methods used in Dimensions and the internal analytical criteria built into CiteSpace to obtain and present the results of the analysis.

Lastly, as most of the documents were never or very infrequently co-cited, the author clusters generated in the study constitute a very active subset of those engaging in the speciality. They consequently afford an approximate representation of the intellectual core but not the entire structure of this research speciality. 


\section{Conclusions}

This study of the most recent developments in altmetrics was based on the construction and analysis of journal and author co-citation networks. The findings showed that research on the subject has intensified steadily since 2012 . The most prominent terms with which the clusters were automatically identified included open knowledge, altmetric collection, web indicator, assessing research, ResearchGate score, open data citation advantage, Google Scholar author citation, share data, academic tweet, Mendeley readership count and social media metrics. The subject area was also described by the terms retrieved with latent semantic indexing, which confirmed the a priori presumption that the speciality is multi-faceted and multi-dimensional. Many studies on altmetrics with a substantial number of citations have been published in PLOS one, Journal of the Association for Information Science and Technology, Nature, Scientometrics, Science and Journal of informetrics. Further to the Dimensions category names in place on the date when the data were gathered, articles classified under the fields Information Systems, Public Health \& Health Services and Sociology were closely related to altmetrics.

Altmetrics is a challenge in scientific communication processes. Identifying journals, authors and subjects enables non-specialist researchers to keep abreast of developments in the speciality. The method described here can be used to generate others in this or other research domains and specialities.

\section{References}

Bailey, David S.; Zanders, Edward D. (2008). "Drug discovery in the era of Facebook-new tools for scientific networking". Drug discovery today, v. 13, n. 19-20, pp. 863-868.

https://doi.org/10.1016/j.drudis.2008.07.003

Bar-Ilan, Judit (2018). "The journal of altmetrics is launched - Editorial”. Journal of altmetrics, v. 1, n. 1, pp. 1-5. https://doi.org/10.29024/joa.5

Barnes, Cameron (2015). "The use of altmetrics as a tool for measuring research impact". Australian academic \& research libraries, v. 46, n. 2, pp. 121-134.

https://doi.org/10.1080/00048623.2014.1003174

Becher, Tony (1989). Academic tribes and territories: intelectual enquiry and the cultures of disciplines. Milton Keynes: SRHE and Open University Press. ISBN: 0335092209

Bode, Christian; Herzog, Christian; Hook, Daniel; McGrath, Robert (2018). A guide to the Dimensions data approach. Cambridge: Digital Science.

https://doi.org/10.6084/m9.figshare.5783094

Bornmann, Lutz; Haunschild, Robin (2016). "Normalization of Mendeley reader impact on the reader- and paper-side: A comparison of the mean discipline normalized reader score (MDNRS) with the mean normalized reader score (MNRS) and bare reader counts". Journal of informetrics, v. 10, n. 3, pp. 776-788.

https://doi.org/10.1016/j.joi.2016.04.015

Boyack, Kevin W.; Klavans, Richard (2010). “Co-citation analysis, bibliographic coupling, and direct citation: Which citation approach represents the research front most accurately?". Journal of the American Society for Information Science and Technology, v. 61, n. 12, pp. 2389-2404.

https://doi.org/10.1002/asi.21419

Bundy, Jacob J.; Hage, Anthony N.; Chick, Jeffrey-Forris B.; Srinivasa, Rajiv N.; Patel, Nischant; Johnson, Evan; Gemmete, Joseph J.; Srinivasa, Ravi N. (2018). "\#Radiology: A 7-year analysis of radiology-associated hashtags". Current problems in diagnostic radiology, v. 47, n. 5, pp. 296-301.

https://doi.org/10.1067/j.cpradiol.2018.04.005

Carpenter, Christopher R.; Cone, David C.; Sarli, Cathy C. (2014). "Using publications metrics to highlight academic productivity and research impact". Academic emergency medicine, v. 21, n. 10, pp. 1160-1172.

https://doi.org/10.1111/acem.12482

Colbert, Gates B.; Topf, Joel; Jhaveri, Kenar D.; Oates, Tom; Rheault, Michelle N.; Shah, Silvi; Swapnil, Hiremath; Sparks, Matthew A. (2018). "The social media revolution in nephrology education". Kidney international reports, v. 3, n. 3, pp. 519-529.

https://doi.org/10.1016/j.ekir.2018.02.003

Chang, Yu-Wei; Huang, Mu-Hsuan; Lin, Chiao-Wen (2015). "Evolution of research subjects in library and information science based on keyword, bibliographic coupling, and co-citation analyses". Scientometrics, v. 105, n. 3, pp. $2071-2087$. https://doi.org/10.1007/s11192-015-1762-8

Chen, Chaomei (2006). "CiteSpace II: Detecting and visualizing emerging trends and transient patterns in scientific literature". Journal of the American Society for Information Science and Technology, v. 57, n. 3, pp. 359-377. 
https://doi.org/10.1002/asi.20317

Chen, Chaomei; Ibekwe-SanJuan, Fidelia; Hou, Jianhua (2010). "The structure and dynamics of cocitation clusters: A multiple-perspective cocitation analysis". Journal of the American Society for Information Science and Technology, v. 61, n. 7, pp. 1386-1409.

https://doi.org/10.1002/asi.21309

Das, Anup-Kumar; Mishra, Sanjaya (2014). "Genesis of altmetrics or article-level metrics for measure efficacy of scholarly communications: Current perspectives". Journal of scientometrics research, v. 3, n. 2, pp. 82-92.

https://doi.org/10.4103/2320-0057.145622

Deerwester, Scott; Dumais, Susan T.; Furnas, George W.; Landauer, Thomas K.; Harshman, Richard (1990). Indexing by latent semantic analysis". Journal of the American Society for Information Science, v. 41, n. 6, pp. 391-407.

https://doi.org/10.1002/(SICI)1097-4571(199009)41:6<391::AID-ASI1>3.0.CO;2-9

Egghe, Leo (2006). "Theory and practise of the g-index". Scientometrics, n. 69, n. 1, pp. 131-152.

https://doi.org/10.1007/s11192-006-0144-7

Erdt, Mojisola; Nagarajan, Aarthy; Joanna-Sin, Sei-Ching; Theng, Yin-Leng (2016). "Altmetrics: An analisis of the stateof-the-art in measuring research impact on social media". Scientometrics, v. 109, n. 2, pp. 1117-1166.

https://doi.org/10.1007/s11192-016-2077-0

Fairclough, Ruth; Thelwall, Mike (2015). "National research impact indicators from Mendeley readers". Journal of informetrics, v. 9, n. 4, pp. 845-859.

https://doi.org/10.1016/j.joi.2015.08.003

Fanelli, Daniele; Glänzel, Wolfgang (2013). "Bibliometric evidence for a hierarchy of the sciences". PLoS one, v. 8, n. 6, e66938.

https://doi.org/10.1371/journal.pone.0066938

Freeman, Linton C. (1977). "A set of measures on centrality based on betweenness". Sociometry, v. 40, n. 1, pp. 35-41. https://doi.org/10.2307/3033543

García-Peñalvo, Francisco J.; García-De-Figuerola, Carlos; Merlo, José A. (2010). “Open knowledge: Challenges and facts". Online information review, v. 34, n. 4, pp. 520-539.

https://doi.org/10.1108/14684521011072963

Gasparyan, Armen-Yuri; Yessirkepov, Marlen; Duisenova, Akmaral; Trukhachev, Vladimir I.; Kostyukova, Elena I; Kitas, George D. (2018). "Researcher and author impact metrics: variety, value, and context". Journal of Korean medical science, v. 33, n. 18, e139.

https://doi.org/10.3346/jkms.2018.33.e139

González-Valiente, Carlos-Luis; Pacheco-Mendoza, Josmel; Arencibia-Jorge, Ricardo (2016). "A review of altmetrics as an emerging discipline for research evaluation". Learned publishing, v. 29, n. 4, pp. 229-238.

https://doi.org/10.1002/leap.1043

Hage, Anthony N.; Chick, Jeffrey-Forris B.; Jeffers, Brian; Srinivasa, Rajiv N.; Gemmete, Joseph J.; Srinivasa, Ravi N. (2018). "\#interventionalradiology". Journal of vascular and interventional radiology, v. 29, n. 5, pp. 699-675.

https://doi.org/10.1016/j.jvir.2017.12.023

Hoffmann, Robert (2008). "A wiki for the life sciences where authorship matters". Nature genetics, v. 40, pp. 1047-1051. https://doi.org/10.1038/ng.f.217

Hou, Jianhua; Yang, Xiucai; Chen, Chaomei (2018). "Emerging trends and new developments in information science: A document co-citation analysis (2009-2016)". Scientometrics, v. 115, n. 2, pp. 869-892.

https://doi.org/10.1007/s11192-018-2695-9

Hua, Fang; Shen, Cenyu; Walsh, Tania; Glenny, Anne-Marie; Worthington, Helen (2017). “Open access: Concepts, findings, and recommendations for stakeholders in dentistry". Journal of dentistry, v. 64, pp. 13-22.

https://doi.org/10.1016/j.jdent.2017.06.012

Hull, Duncan; Pettifer, Steve R.; Kell, Douglas B. (2008). “Defrosting the digital library: Bibliographic tools for the next generation web". PLoS computational biology, v. 4, n. 10, e1000204.

https://doi.org/10.1371/journal.pcbi.1000204

Kalia, Vivek; Ortiz, Daniel A.; Patel, Amy K.; Moriarity, Andrew K.; Canon, Cheri L.; Duszak J. R., Richard (2018). “Leveraging Twitter to maximize the radiology meeting experience". Journal of the American College of Radiology, v. 15, n. 1, part B, pp.177-183.

https://doi.org/10.1016/j.jacr.2017.10.022 
Kamada, Tomihisa; Kawai, Satoru (1989). "An algorithm for drawing general undirected graphs". Information processing letters, v. 31, n. 1, pp. 7-15.

https://doi.org/10.1016/0020-0190(89)90102-6

Kaplan, Andreas M.; Haenlein, Michael (2010). "Users of the world, unite! The challenges and opportunities of social media. Business horizons, v. 53, n. 1, pp. 59-68.

https://doi.org/10.1016/j.bushor.2009.09.003

Kleinberg, Jon (2002). "Bursty and hierarchical structure in streams". En: Proceedings of the $8^{\text {th }}$ ACM Sigkdd intl conf on knowledge discovery and data mining, pp. 91-101. New York: ACM Press.cy

https://www.cs.cornell.edu/home/kleinber/bhs.pdf

Koltay, Tibor; Špiranec, Sonja; Karvalics, László Z. (2015). “The shift of information literacy towards research 2.0”. The journal of academic librarianship, v. 41, n. 1, pp. 87-93.

https://doi.org/10.1016/j.acalib.2014.11.001

Kousha, Kayvan; Thelwall, Mike (2015). "Web indicators for research evaluation. Part 3: Books and non-standard outputs". El profesional de la información, v. 24, n. 6, pp. 724-736.

https://doi.org/10.3145/epi.2015.nov.04

Kousha, Kayvan; Thelwall, Mike (2016). "Can Amazon.com reviews help to assess the wider impacts of books?". Journal of the Association for Information Science and Technology, v. 67, n. 3, pp. 566-581.

https://doi.org/10.1002/asi.23404

Leydesdorff, Loet (2008a). “Journals as retention mechanism of scientific growth". Research trends, v. 31, n. 6.

Leydesdorff, Loet (2008b). “On the normalization and visualization of autor co-citation data: Salton's cosine versus the Jaccard Index". Journal of the American Society for Information Science and Technology, v. 59, n. 1, pp. 77-85.

https://doi.org/10.1002/asi.20732

Leydesdorff, Loet; Wagner, Caroline S.; Bornmann, Lutz (2018). "Betweenness and diversity in journal citation networks as measures of interdiscipInarity- a tribute to Eugene Garfield. Scientometrics, v. 114, n. 2, pp. 567-592.

https://doi.org/10.1007/s11192-017-2528-2

Liu, Guoying; Yang, Le (2019). "Popular research topics in the recent journal publications of library and information science". Journal of academic librarianship, v. 45, n. 3, pp. 278-287.

https://doi.org/10.1016/j.acalib.2019.04.001

Logghe, Heather J.; Selby, Luke V.; Boeck, Marissa A.; Stamp, Nikki L.; Chuen, Jason; Jones, Christian (2018). "The academic tweet: Twitter as a tool to advance academic surgery". Journal of surgical research, v. 226, pp. VIII-XII.

https://doi.org/10.1016/j.jss.2018.03.049

Mane, Ketan K.; Börner, Katy (2004). "Mapping topics and topic burst in PNAS". Proceedings of the National Academy of Sciences of the United States of America, v. 101, suppl. 1, pp. 5287-5290.

https://doi.org/10.1073/pnas.0307626100

Mas-Bleda, Amalia; Aguillo, Isidro F. (2015). La web social como nuevo medio de comunicación y evaluación científica. Barcelona: UOC. ISBN: 9788490649220

McCain, Katherine W. (1991). "Mapping economics through the journal literature: An experiment in journal cocitation analysis". Journal of the American Society for Information Science, v. 42, n. 4, pp. 290-296.

https://doi.org/10.1002/(SICI)1097-4571(199105)42:4<290::AID-ASI5>3.0.CO;2-9

Morris, Steven A.; Van-der-Veer-Martens, Betsy (2008). "Mapping research specialties". Annual review of information science and technology, v. 42, n. 1, pp. 213-295.

https://doi.org/10.1002/aris.2008.1440420113

Newman, Mark E. J. (2006). "Finding community structure in networks using the eigenvectors of matrices". Physical review $E$, v. 74, n. 3, pp. 1-22.

https://doi.org/10.1103/PhysRevE.74.036104

NISO (2016). NISO-RP-25-2016. Outputs of the NISO alternative assessment metric project. National Information Standards Organization.

https://www.niso.org/publications/rp-25-2016-altmetrics

Onyancha, Omwoyo-Bosire (2018). "Forty-five years of LIS research evolution, 1971-2015: An informetrics study of the autor-supplied keywords". Publishing research quarterly, v. 34, n. 3, pp. 456-470.

https://doi.org/10.1007/s12109-018-9590-3

O’Reilly, Tim (2006). What is Web 2.0. 
https://www.oreilly.com/pub/a/web2/archive/what-is-web-20.html

Orduña-Malea, Enrique; Delgado-López-Cózar, Emilio (2018). “Dimensions: Re-discovering the ecosystem of scientific information". El profesional de la información, v. 27, n. 2, pp. 420-431.

https://doi.org/10.3145/epi.2018.mar.21

Piwowar, Heather A.; Vision, Todd J. (2013). “Data reuse and the open data citation advantage”. Peerj, v. 1, e175. https://doi.org/10.7717/peerj.175

Priem, Jason (2014). "Altmetrics". En: Cronin, Blaise; Sugimoto, Cassidy R. (eds.). Beyond bibliometrics. Cambridge: MIT Press, pp. 263-287. ISBN: 9780262026796

Priem, Jason; Groth, Paul; Taraborelli, Dario (2012). “The altmetrics collection”. PLoS one, v. 7, n. 11, e48753. https://doi.org/10.1371/journal.pone.0048753

Priem, Jason; Taraborelli, Dario; Groth, Paul; Neylon, Cameron (2010). "Altmetrics: a manifesto". Altmetrics, 26 October. http://altmetrics.org/manifesto

Rosenkrantz, Andrew B.; Ayoola, Abimbola; Duszak J. R., Richard (2017) "Alternative metrics ("altmetrics") for assessing article impact in popular general radiology journals". Academic radiology, v. 24, n. 7, pp. 891-897.

https://doi.org/10.1016/j.acra.2016.11.019

Rousseeuw, Peter J. (1987). "Silhouettes: A graphical aid to the interpretation and validation of cluster análisis". Journal of computational and applied mathematics, v. 20, pp. 53-65.

https://doi.org/10.1016/0377-0427(87)90125-7

Schvaneveldt, Roger W.; Durso, Francis T.; Dearholt, Donald W. (1989). "Network structures in proximity data". Psychology of learning and motivation, v. 24, pp. 249-284.

https://doi.org/10.1016/S0079-7421(08)60539-3

Sugimoto, Cassidy R.; Work, Sam; Larivière, Vincent; Haustein, Stefanie (2017). "Scholarly use on social media and altmetrics: A review of the literature". Journal of the Association for Information Science and Technology, v. 68, n. 9, pp. 2037-2062.

https://doi.org/10.1002/asi.23833

Thelwall, Mike (2012). "A history of webometrics". Bulletin of_the Association for Information Science and Technology, v. 38, n. 6, pp. 18-23.

https://doi.org/10.1002/bult.2012.1720380606

Thelwall, Mike (2016). "The discretised lognormal and hooked power law distributions for complete citation data: Best options for modelling and regression". Journal of informetrics, v. 10, n. 2, pp. 336-346.

https://doi.org/10.1016/j.joi.2015.12.007

Thelwall, Mike (2017). Web indicators for research evaluation. A practical guide. Willinston: Morgan and Claypool. ISBN: 9781627059176

https://doi.org/10.2200/S00733ED1V01Y201609ICR052

Thelwall, Mike; Fairclough, Ruth (2015). "Geometric journal impact factors correcting for individual highly cited articles". Journal of informetrics, v. 9, n. 2, pp. 263-272.

https://doi.org/10.1016/j.joi.2015.02.004

Thelwall, Mike; Kousha, Kayvan (2015a). "Web indicators for research evaluation. Part 1: Citations and links to academic articles from the Web". El profesional de la información, v. 24, n. 5, pp. 587-606.

https://doi.org/10.3145/epi.2015.sep.08

Thelwall, Mike; Kousha, Kayvan (2015b). "Web indicators for research evaluation. Part 2: Social media metrics". El profesional de la información, v. 24, n. 5, pp. 607-620.

https://doi.org/10.3145/epi.2015.sep.09

Thelwall, Mike; Vaughan, Liwen; Björneborn, Lennart (2005). "Webometrics". Annual review of information science and technology, v. 39, n. 1, pp. 81-135.

https://doi.org/10.1002/aris.1440390110

Todeschini, Roberto; Baccini, Alberto (2016). Handbook of bibliometric indicators: Quantitative tools for studying and evaluating research. Weinheim: Wiley-VCH. ISBN: 9783527337040

https://doi.org/10.1002/9783527681969

Waltman, Ludo; Van-Eck, Nees-Jan (2012). "A new methodology for constructing a publication-level classification system of science". Journal of the American Society for Information Science and Technology, v. 63, n. 12, pp. $2378-2392$.

https://doi.org/10.1002/asi.22748 
Weller, Katrin (2015). "Social media and altmetrics: An overview of current alternative approaches to measuring scholarly impact". En: Wellpe, Isabell M.; Wollersheim, Jutta; Ringelhan, Stefanie; Osterloh, Margit. Incentives and performance. Heidelberg: Springer, pp. 261-275. ISBN: 9783319097848

https://doi.org/10.1007/978-3-319-09785-5_16

White, Howard D.; Griffith Bellver C. (1981). "Author cocitation: A literature measure of intellectual structure". Journal of the American Society for Information Science, v. 32, n. 3, pp. 163-171.

https://doi.org/10.1002/asi.4630320302

Williams, Ann E. (2017). "Altmetrics: An overview and evaluation". Online information review, v. 41, n. 3, pp. $311-317$. https://doi.org/10.1108/OIR-10-2016-0294

White, Howard, D. (2003). "Pathfinder networks and author cocitation análisis: A remapping of paradigmatic information scientists". Journal of the American Society for Information Science and Technology, v. 54, n. 5, pp. 423-434. https://doi.org/10.1002/asi.10228

Whitley, Richard (2000). The intellectual and social organization of the sciences. New York: Oxford University Press. ISBN: 0199240450

Yan, Erjia; Ding, Ying (2012). "Scholarly network similarities: How bibliographic coupling networks, citation networks, cocitation networks, topical networks, coauthorship networks, and coword networks relate to each other". Journal of the American Society for Information Science and Technology, v. 63, n. 7, pp. 1313-1326.

https://doi.org/10.1002/asi.22680

Yang, Siluo; Han, Ruizhen; Wolfram, Dietmar; Zhao, Yuehua (2016). "Visualizing the intellectual structure of information science (2006-2015): Introducing author keyword coupling analysis". Journal of informetrics, v. 10, n. 1, pp.132-150. https://doi.org/10.1016/j.joi.2015.12.003

Zhao, Dangzhi (2009). "Mapping library and information science: Does field delineation matter?". Proceedings of the American Society for Information Science and Technology, v. 46, n. 1, pp. 1-11. https://doi.org/10.1002/meet.2009.1450460279

Zhou, Qingqing; Zhang, Chengzhi; Zhao, Star X.; Chen, Bikun (2016). “Measuring book impact based on the multi-granularity online review mining". Scientometrics, v. 107, n. 3, pp. 1435-1455.

https://doi.org/10.1007/s11192-016-1930-5

La Fundación Biblioteca Social es una institución sin ánimo de lucro que se constituyó en el año 2014. Tiene como objetivo contribuir a compensar los desequilibrios sociales apoyando proyectos que llevan a cabo las bibliotecas públicas, dirigidos a los sectores más vulnerables de la sociedad

\section{¿Colaboras?}

fundacionbibliotecasocial.org info@fundacionbibliotecasocial.org

3 @Biblio_Social

f FundacionBibliotecasSocial

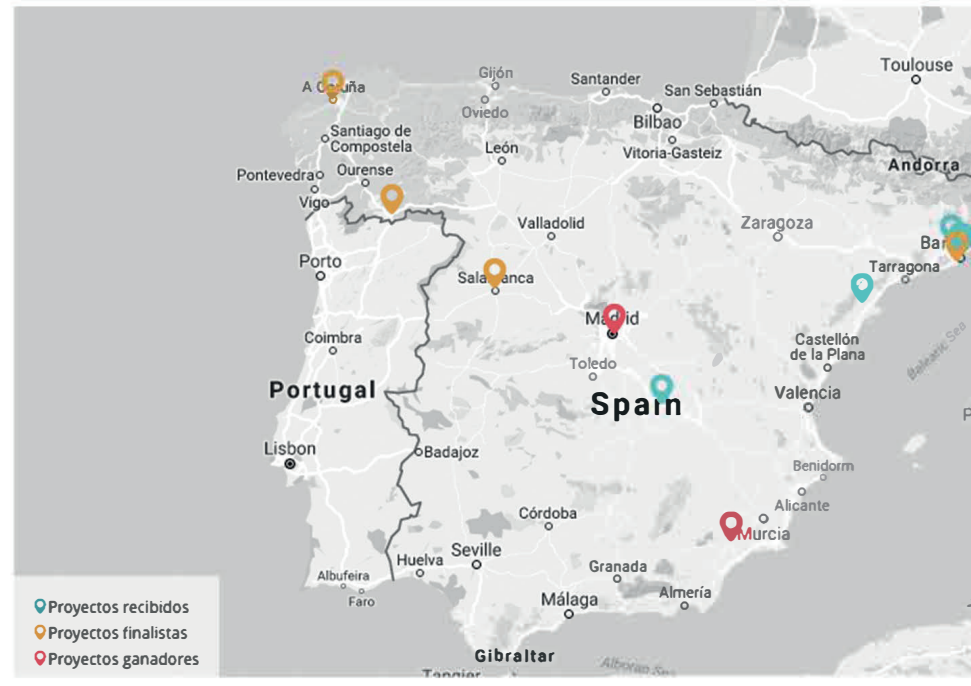

Mapa de proyectos de bibliotecas públicas para la inclusión social. 2016

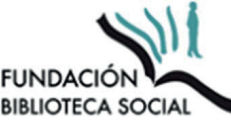

